\title{
Encouraging interviewees to say more and deception: The Ghostwriter method
}

Sharon Leal

Aldert Vrij

Haneen Deeb

Kevin Kamermans

Psychology Department, University of Portsmouth

Author Note

Sharon Leal, Aldert Vrij, Department of Psychology, University of

Portsmouth.

This work was funded by the Centre for Research and Evidence on Security Threats (ESRC Award: ES/N009614/1)

Correspondence concerning this article should be addressed to Sharon Leal, Department of Psychology, University of Portsmouth, King Henry Building, King Henry 1 Street, PO1 2DY, Hants, United Kingdom. Email: sharon.leal@port.ac.uk 


\begin{abstract}
Background. We examined a new method to encourage interviewees to say more, the Ghostwriter method, and examined its effect on eliciting information and cues to deceit.

Method. A total of 150 truth tellers and liars either told the truth about a trip they made in the last twelve months or pretended to have made such a trip. They were allocated to a Control condition, a 'Be detailed' condition in which they were encouraged to report even small details and a Ghostwriter condition in which they were told to imagine talking to a ghostwriter. The dependent variables were details, complications, common knowledge details, self-handicapping strategies, proportion of complications, plausibility and verifiable sources.
\end{abstract}

Results. The Ghostwriter condition elicited more details and revealed in plausibility a stronger cue to deceit than the other two conditions.

Conclusion. The Ghostwriter method appears to be a promising tool for eliciting information and cues to deceit.

Keywords

Encouraging interviewees to say more

Eliciting information

Interviewing to detect deception

Proportion of complications

Verifiable sources 


\section{Encouraging interviewees to say more and deception: The Ghostwriter method}

In the last decade researchers started to design interview protocols aimed at eliciting or enhancing cues to deceit (Vrij \& Granhag, 2012). Prime examples are Assessment Criteria Indicative of Deception (Colwell, Hiscock-Anisman, \& Fede, 2013), Cognitive Credibility Assessment (Vrij, Fisher, \& Blank, 2017a), the Strategic Use of Evidence (Granhag \& Hartwig, 2015; Hartwig, Granhag \& Luke, 2014) and the Verifiability Approach (Nahari, 2018; Vrij \& Nahari, 2019). Cognitive Credibility Assessment includes the 'encouraging interviewees to say more' tool. Its core is that truth tellers do not spontaneously report all they know in interviews (Vrij, Hope, \& Fisher, 2014), because (i) they have difficulties with retrieving the information from their memory and/or because (ii) they are unaware how much detail they should provide. Inviting interviewees to sketch while narrating is a method to facilitate retrieval from memory (Vrij et al., 2018c), whereas exposing interviewees to a Model Statement is a method to raise interviewees' expectations about how much information they need to provide (Leal, Vrij, Warmelink, Vernham, \& Fisher, 2015). The Ghostwriter method, introduced in this article, is another method to raise interviewees' expectations about how much information they are expected to provide in an interview. We developed it after discussing the Model Statement method with practitioners.

A Model Statement is a detailed example of an account unrelated to the topic of investigation (Leal et al., 2015). Exposing interviewees to a Model Statement works as a social comparison (Festinger, 1954) and raises the expectations amongst interviewees about how much information they are expected to report (Ewens et al., 2016). It raises such expectations in truth tellers as well as liars, with the result that both groups report a similar amount of extra detail after being exposed to a Model 
Statement (Vrij, Leal, \& Fisher, 2018a). However, the types of detail truth tellers and liars report after exposure to a Model Statement appear to differ. Truth tellers reported more complications than liars (Vrij et al., 2107b, 2018a), whereas liars reported more peripheral details than truth tellers (Leal, Vrij, Deeb, \& Jupe, 2018a; Vrij et al., 2018a). Truth tellers' stories also sounded more plausible than liars' stories (Leal et al., 2015).

When discussing the Model Statement with practitioners, two issues came to light. First, they expressed a desire to receive more techniques that will encourage interviewees to say more. The reason is that eliciting as much information as possible is a key aspect of investigative interviewing (Fisher, 2010; Vrij et al., 2014).

Practitioners consider it a bonus that a Model Statement not only results in more information, but also in cues to deceit. Second, some practitioners are reluctant to use an existing Model Statement and prefer to design their own Model Statement. Everyone has a preference what type of story s/he likes and/or what story comes close to his/her own experiences and perhaps this likeability and recognition affects what s/he wants to use. That could easily lead to problems, particularly when practitioners make up a Model Statement on the spot that (i) does not sound authentic enough, (ii) is not detailed enough and (iii) is topic-wise too close to the topic of investigation, so that it could give liars an idea about what details to report (Vrij et al., 2018a).

As an alternative to a Model Statement, an interviewer could perhaps instruct the interviewee to report all details they remember, even details they consider not important. We are not convinced that this would be effective. This request is an instruction and instructions are not always easy to follow (Vrij et al., 2018a). A better result could be achieved by providing an example -such as the Model Statementbecause examples are easier to follow (Vrij et al., 2018a). A better alternative than the 
instruction to be detailed could be to ask the interviewee to imagine that $\mathrm{s} / \mathrm{he}$ is talking to a ghostwriter. Most people have probably heard about this concept before and probably know how it works: When talking to a ghostwriter it would be essential to include all details, even the tiny insignificant ones, because part of the ghostwriter's skill lies in determining what the most interesting parts of a story are. A Ghostwriter instruction may be effective because it gives the interviewee maximum freedom to report his/her story in whatever way s/he wants, because the ghostwriter will cut out the uninteresting parts, and will structure and polish the remaining parts. The unstructured nature of reporting to a Ghostwriter may also result in associations in which one memory may lead to another memory and no reluctance on the interviewee's side to report these associations.

Similar to a Model Statement, a ghostwriter instruction could encourage interviewees to say more. However, as with the Model Statement, this would probably be the case for truth tellers and liars alike. Similar to Model Statement research, we therefore examined the types of detail truth tellers and liars reported (complications, common knowledge details and self-handicapping strategies, Vrij et al., 2017b) and plausibility (Leal et al., 2015).

Vrij et al. (2017b) found that truth tellers reported more complications than liars, particularly after listening to a Model Statement (Veracity x Model Statement interaction). A complication is an occurrence that makes a situation more difficult to report than necessary (Vrij et al., 2018d) ("The hotel room was double booked, so they had to find us a different hotel"). Truth tellers are thought to report more complications than liars because liars prefer to keep their stories simple (Hartwig, Granhag, \& Strömwall, 2007), whereas reporting complications makes the story more complex. Truth tellers may have reported more complications than liars particularly 
after listening to a Model Statement, because reporting complications is typically not necessary to describe main events. Therefore, only after being encouraged to tell all they remember, truth tellers will start to report complications.

Common knowledge details are strongly invoked stereotypical information about events (Vrij et al., 2018d) ("I went to the Van Gogh museum in Amsterdam and saw many Van Gogh's paintings"). Liars are thought to report more common knowledge details than truth tellers. Liars lack the personal experience to add meaningful personal details when describing an activity. Self-handicapping strategies are justifications as to why someone is not able to provide information (Vrij et al., 2018d). ('I can't tell you the name of the street, it has a Dutch name and I don't speak Dutch"). Liars are thought to report more self-handicapping strategies than truth tellers. For liars, not providing too many details sounds like an attractive strategy, but if they do not give enough details they run the risk they will not be believed. A possible solution is to offer a justification for not being able to report details. Vrij et al. (2017b) found no Veracity x Model Statement interaction effects for common knowledge details and self-handicapping strategies.

Leal et al. (2015) found that the statements by both truth tellers and liars were considerably longer in the Model Statement present than in the Model Statement absent condition. Furthermore, in the Model Statement present condition, truth tellers' stories sounded more plausible than liars' stories, whereas no difference in plausibility emerged in the Model Statement absent condition. To explain these findings, Leal et al. (2015) argued that in the Model Statement present condition, liars apparently failed to add many details to their stories that also sounded plausible.

Finally, we examined reporting verifiable sources, which -to our knowledgehas never been examined before in a method aimed to encourage interviewees to say 
more. Verifiable sources are derived from the Verifiability Approach (VA) (Nahari, 2018; Vrij \& Nahari, 2019). The VA is based on a dilemma that liars face. On the one hand, liars prefer to provide many details, because providing details makes a sincere impression on observers. On the other hand, liars do not wish to mention too many details out of fear that these details may reveal their deceit. A solution for this dilemma is to provide details that cannot be verified (Nahari, 2018). Research has shown that liars indeed report fewer details that can be checked (e.g., "I saw my friend Zvi earlier this morning”) and more details that cannot be checked ("Several people walked by when I sat there”) (Nahari, Vrij, \& Fisher, 2014). Verifiable details are activities that an interviewee says i) s/he carried out with or ii) was witnessed by a named or otherwise identifiable person, or iii) was recorded on CCTV. In addition, (iv) activities that leave a trace (mobile phone call, text, debit/credit card purchases and receipts) are also considered verifiable. Instead of counting the number of verifiable details, Leal et al. (2018b) counted the number of verifiable sources (e.g. 'my friend Zvi' in the example above). They argued that investigators probably find it easier in real time to count the number of verifiable sources than the number of verifiable details. Verifiable sources and verifiable details are related to each other as only a verifiable source leads to verifiable details. Leal et al. (2018b) found that truth tellers reported more verifiable sources than liars.

\section{Hypotheses}

We tested the following hypotheses, which mirrored the findings obtained in Model Statement research conducted to date:

- Hypothesis 1: Across interview conditions, truth tellers will report more details (1a), more complications (1b) and more verifiable sources (1c) than liars. They will also obtain a higher proportion of complications score (1d) than liars (complications / 
[complications + common knowledge details + self-handicapping strategies]) and their stories will sound more plausible than liars' stories (1e).

- Hypothesis 2: Across interview conditions, liars will report more common knowledge details (2a) and more self-handicapping strategies (2b) than truth tellers.

- Hypothesis 3: The Ghostwriter condition will result in more details than the control conditions.

- Hypothesis 4: We further predicted interaction effects; more specifically that the effects predicted in Hypotheses $1 \mathrm{~b}$ and 1e will be most pronounced in the ghostwriter condition. Thus, particularly in the Ghostwriter condition, truth tellers will report more complications than liars (4a) and truth tellers' stories will sound more plausible than liars' stories (4b).

\section{Participants}

\section{Method}

A total of 150 university students and personnel (49 males, 98 females and three unknown) took part in the study. Their age ranged from 18 to 56 years with an average age of $M=24.41$ years $(S D=7.07)$.

\section{Procedure}

We used the same procedure as Vrij et al., 2017b, 2018a, c). Participants were recruited via an advert on the university intranets and advertisement leaflets distributed in university buildings. The advert explained that the experiment would require participants to tell the truth or lie about a trip away that they may (or may not) have taken within the last year. Participants were randomly allocated to the veracity conditions. Truth tellers were asked to think about a city trip away during the last 12 months that included at least two nights. They were also told that this trip could not involve going home. All truth tellers said that they had made such a city trip in the last 12 months. Liars were asked to make up a story about a city trip away during the 
last 12 months that included at least two nights. It should be a city they had never been to before. We gave them a city to discuss, a city previously discussed by a truth teller, so that the truth tellers' and liars' trips would match. We checked with liars that they had never made the city trip we asked them to discuss.

Participants were then given a computer with internet access. Participants were given twenty minutes to prepare for their interview in which they were allowed to make notes. Participants were also told that it was important to be convincing because, if they did not appear convincing, they would be asked to write a statement about what they told the interviewer in the interview. In a pre-interview questionnaire the truth tellers and liars rated on three 7-point scale items their thoroughness of preparation: 1 (shallow) to 7 (thorough), 1 (insufficient) to 7 (sufficient), 1 (poor) to 7 (good). The answers to the three scales were averaged $($ Cronbach's alpha $=.84)$ into an overall 'thoroughness' score. Participants were also asked how motivated they were to perform well during the interview $(1=$ not at all motivated and $5=$ very motivated). Finally, they were asked whether they thought they were given enough time to prepare themselves for the interview $(1=$ insufficient and $7=$ sufficient $)$.

Participants were randomly allocated to one of three interview conditions. Just before the interview started, the experimenter informed the interviewer which city the participant would discuss. The interviewer then started the interview by saying: "I understand from my colleague that you have visited $<$ city $>$. I am just going to ask you one question, so make sure that you include all the information you want to convey in your answer." In the Control condition the interviewer then asked the following free recall question: "Could you please tell me in as much detail as possible everything that happened from the moment you started your trip to the moment you left?" In the 
Be detailed condition an instruction was added to the free recall question: "Please think of all the details, big and small, and include these in your account."

In the Ghostwriter condition the concept of a Ghostwriter was introduced (a person whose job it is to write books or articles for another individual). It was then explained that it is essential for a ghostwriter to hear all the details because part of the ghostwriter's skill lies in determining what the ghostwriter thinks are the most interesting parts of a story. The interviewer then said: "What we would like you to do is to imagine that you will be speaking to a ghostwriter about the trip you recently made. Please think of all the details, big and small, and include these in your account. Therefore, if a ghostwriter were to listen to your account they should, in theory, be able to make a comprehensive story regarding your trip. Do you understand?" When the participant said yes the interviewer continued with the free recall question: "Whilst imagining you are talking to a ghostwriter, could you please tell me in as much detail as possible everything that happened from the moment you started your trip to the moment you left?"

After the interview, participants completed a post-interview questionnaire, in which they were asked to indicate the extent to which they told the truth in the interview on an 11-point Likert scale ranging from $0 \%$ to $100 \%$.

\section{Coding}

The coders, blind to the Veracity condition, were taught the coding scheme by the first author who is very experienced in verbal coding. One coder read the transcripts and coded each detail in the interview. A detail was defined as a unit of information about the trip the interviewee allegedly had made. The following answer has seven details: "I went to the Isle of Wight and went to Shanklin, we got on the 


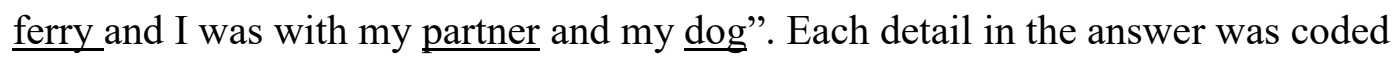
only once; thus repetitions were not coded.

A second coder coded complications, common knowledge details and selfhandicapping strategies in all transcripts. Similar to the details coding, repetitions were not coded. A complication is an occurrence that makes a situation more difficult than necessary (Vrij et al., 2018d). Example of complications are (a) "We were staying at the Queen's hotel, but there was no car park for that hotel so we had to drive to another one"; (b) "We stayed in a hotel because our friends' house was too small to accommodate us"; and (c) "The taxi driver argued with another taxi driver on the road and we were stuck in the taxi”. Common knowledge details refer to strongly invoked stereotypical knowledge about events (Vrij et al., 2018d). Examples of common knowledge details are: (d) "We stayed at the hotel and had drinks at the hotel bar", (e) "We went around town just seeing all the sights and all the gift shops" and (f) "We went to the beach and just relaxed there". Self-handicapping strategies refer to justifications as to why someone is not able to provide information. Examples of self-handicapping strategies are: (g) "We had some lunch and then we went to.... my memory is terrible, sorry", (h) "On the train we just slept because we were so tired" and (i) “We didn’t have much to do, because we don't really plan very well”. Based on these three scores we computed the proportion of complications score (complications / [complications + common knowledge details + self-handicapping strategies])

The second coder also coded plausibility and verifiable sources. Plausibility was defined as 'How likely is it that the activities happened in the way described'. This was coded on a 7-point Likert scale ranging from 1 (very implausible) to 7 (very plausible). Verifiable sources are: i) people with whom the interviewee carried out 
activities or ii) whom witnessed their activities; (iii) CCTV camera footage or iv) activities that leave a trace such as the use of debit cards, mobile phones, or computers. Nearly all verifiable sources in the present experiment fell under the first category ("I went with my husband to Brighton"). In this sentence 'husband' is the verifiable source; in comparison, the sentence contains three verifiable details (I, husband, Brighton).

A third coder coded 50 transcripts independently from the two coders. Interrater reliability between this coder and each of the other two coders (Intraclass correlation coefficient, ICC, Single Measures) was calculated using the two-way random effects model measuring consistency as follows: for details $(\mathrm{ICC}=.69)$, for complications $(\mathrm{ICC}=.76)$, for common knowledge details $(\mathrm{ICC}=.89)$, for selfhandicapping strategies $(\mathrm{ICC}=.66)$, for plausibility $(.78)$, and for verifiable sources $(\mathrm{ICC}=.95)$

\section{Results}

Motivation, preparation time, preparation thoroughness and percentage of truth telling

A 2 (Veracity) x 3 (Interview Instructions) MANOVA was carried out with motivation, preparation time, preparation thoroughness and percentage of truth telling as dependent variables. The analysis revealed significant main effects for Veracity, $F(4,141)=200.28, p<.001, \eta_{p}{ }^{2}=.85$ and interview Instructions, $F(8,280)=2.90, p$ $=.004, \eta_{p}{ }^{2}=.14$ and also a significant Veracity X Interview Instructions interaction effect, $F(8,280)=3.09, p=.002, \eta_{p}^{2}=.13$.

The Veracity results are presented in Table 1. Truth tellers were more motivated than liars and liars thought more than truth tellers that the preparation time they were given was sufficient. Truth tellers also reported that they had been more 
truthful than liars in the interviews. No Veracity differences emerged in preparation thoroughness. Motivation was measured on a 5-point Likert scale and preparation time and preparation thoroughness on 7-point Likert scales. The grand mean shows that participants were well motivated $(M=4.35, S D=0.64)$, though they were given sufficient preparation time $(M=5.67, S D=1.49)$ and rated their preparation as moderately thorough $(M=4.56, S D=1.48)$. Even liars' motivation was high and significantly above the middle point $(3)$ of the scale, $t(76)=16.13, p<.001$. Same applies to preparation time, $t(76)=13.19, \mathrm{p}<.001$, and preparation thoroughness $t(76)=6.27, \mathrm{p}<.001$

The significant Interview Instructions results are presented in Table 2. Participants in the Be detailed condition were more motivated and thought that their planning was more thorough than participants in the two other conditions who did not differ from each other.

A significant Veracity x Interviewer Instructions interaction effect emerged for preparation time. In the control condition, liars found $(M=6.14, S D=1.15,95 \%$ CI $[5.62,6.66])$ that their preparation time was more sufficient than truth tellers $(M=$ $5.04, S D=1.79,95 \% \mathrm{CI}[4.47,5.62])$ and the same pattern of results occurred in the Ghostwriter condition (liars: $M=6.32, S D=0.90,95 \%$ CI [5.77, 6.87]; truth tellers: $M=4.92, S D=1.69,95 \% \mathrm{CI}[4.38,5.46])$. In the Be detailed condition, truth tellers $(M=6.20, S D=1.15,95 \% \mathrm{CI}[5.65,6.75])$ thought they had more sufficient preparation time than liars $(M=5.26, S D=1.54,95 \%$ CI $[4.69,5.84])$.

When we added motivation, preparation thoroughness and preparation time as covariates in the hypotheses-testing analyses, none of the covariate effects were significant, all $F$ 's $<3.02$, all $p$ 's $>.080$. We therefore present in the hypotheses testing section the analysis without the covariates included. 


\section{Hypotheses Testing}

A 2 (Veracity) x 3 (Interview Instructions) MANOVA was carried out with details, complications, common knowledge details, self-handicapping strategies, plausibility and verifiable sources as dependent variables. The analysis revealed significant main effects for Veracity, $F(6,139)=6.16, p<.001, \eta_{p}{ }^{2}=.21$ and for Interview Instructions, $F(12,278)=2.52, p=.004, \eta_{p}{ }^{2}=.10$. The Veracity $\mathrm{X}$ Interview Instructions interaction effect was not significant, $F(12,278)=0.93, p=$ $.515, \eta_{p}^{2}=.04$

Table 1 about here

The univariate main effects for Veracity are reported in Table 1. We also report Cohen $d$-values and Bayes Factor statistics. A $p$-value provides information about the statistical relevance but not about the practical importance of an effect (Du Prel, Hommel, Röhrig, \& Blettner, 2009; Fritz, Morris, \& Richler, 2012). In this article, we are interested in the practical relevance of the effect and $d$-values are indicators of practical relevance (Fritz et al., 2012). Bayes factor analysis is a method to test the probability of the observed data under the null hypothesis compared to the alternative hypothesis (Wetzels \& Wagenmakers, 2012). A BF 10 smaller than 1 indicates evidence for the absence of an effect (support of the null hypothesis). According to the cut-off thresholds provided by Jeffreys (1961), BFs between 1 and 3 suggest weak evidence, BFs between 3 and 10 suggest strong evidence and BFs $>10$ very strong evidence for the alternative hypothesis. We used the default Cauchy's prior of .707 for the Bayesian $t$-tests (Lakens, 2016).

Truth tellers reported more details and more complications than liars, whereas liars reported more common knowledge details than truth tellers. Finally, truth tellers' stories sounded more plausible than liars' stories. The effect sizes for these four 
variables were medium to large and the Bayes Factor analyses showed very strong support for the alternative hypotheses in all four cases. This supports Hypotheses 1a, 1b, 1e and 2a. The Bayes Factor analyses showed support for the null hypotheses for self-handicapping strategies and checkable sources.

Table 2 about here

The univariate main effects for Interview Instructions are presented in Table 2. Significant differences emerged for details and plausibility. The Ghostwriter condition resulted in more details than the Control condition $(d=0.66,95 \%$ CI $[0.25$, 1.05], $\left.\mathrm{BF}_{10}=25.91\right)$ and the Be detailed condition $(d=0.79,95 \% \mathrm{CI}[0.37,1.19]$, $\left.\mathrm{BF}_{10}=141.59\right)$, whereas the Control and Be detailed conditions did not differ from each other $\left(d=0.17,95 \%\right.$ CI $\left.[-0.22,0.56], \mathrm{BF}_{10}=0.29\right)$. This supports Hypothesis 3 . The stories in the Ghostwriter condition also sounded more plausible than the stories in the Control condition $\left(d=0.48,95 \% \mathrm{CI}[0.08,0.87], \mathrm{BF}_{10}=2.77\right)$, and the $\mathrm{Be}$ detailed condition $\left(d=0.61,95 \% \mathrm{CI}[0.20,1.00], \mathrm{BF}_{10}=11.02\right)$, whereas the Control and Be detailed conditions did not differ from each other $(d=0.08,95 \%$ CI $[-0.31$, 0.47], $\left.\mathrm{BF}_{10}=0.28\right)$.

Also at a univariate level, none of the interaction effects were significant, all $F$ 's $<2.14$, all $p$ 's $>.122$, but this refers to any type of interaction. As we predicted in Hypothesis 4 a directional effect for complications and plausibility with specific group differences based on theory and research, planned contrasts were conducted to explore potential group differences (e.g. Deeb et al., 2017; Nahari \& Ben-Shakhar, 2011; Leal et al., 2018a). The Bayes Factor analyses (Table 1) showed that particularly in the Ghostwriter condition, truth-tellers sounded significantly more plausible than liars, supporting Hypothesis 4 . The Veracity effects for complications were similar in all three Interview Instruction conditions, which rejects Hypothesis 4a. 
For completeness, we also report in Table 1 the results for the remaining four variables.

Plausibility scores by definition are derived from speech content. We correlated the speech cues that were coded with plausibility to examine to what extent these cues influenced plausibility. The Pearson correlations showed that plausibility was positively correlated with complications $(r=.63, p<.001)$, details $(r=.58, p<$ $.001)$ and verifiable sources $(r=.43, p<.001)$ and negatively correlated with common knowledge details $(r=-.36, p<.001)$. Plausibility was not correlated with self-handicapping strategies $(r=-.06, p=.508)$.

A 2 (Veracity) x 3 (Interview Instructions) ANOVA was carried out with proportion of complications as the dependent variable. The analysis revealed a significant main effect for Veracity, $F(1,144)=41.98, p<.001, \eta_{p}{ }^{2}=.23$. The main Interview Instructions effect, $F(2,144)=0.99, p=.375, \eta_{p}{ }^{2}=.01$, and the Veracity $\mathrm{X}$ Interview Instructions interaction effect, $F(2,144)=0.63, p=.534, \eta_{p}{ }^{2}=.01$, were not significant. Table 1 shows that truth tellers obtained a higher proportion of complications score than liars, supporting Hypothesis 1d.

\section{Discussion}

We introduced a new technique to encourage interviewees to say more, the Ghostwriter method, and found that it elicited information as well as cues to deceit. A tool that elicits both information and cues to deceit is perhaps the most desirable tool as it fulfills the two main aims of an investigative interview: Elicit as much information as possible from interviewees and be able to assess whether the provided information is true (Brandon, 2011, 2014; Loftus, 2011). Eliciting as much information as possible is in the literature primarily introduced as a good interview 
outcome in witness interviews (Fisher, 2010) and in intelligence interviews (Vrij et al., 2017c) and a Ghostwriter method may be primarily suitable in such interviews.

Regarding eliciting information, the Ghostwriter condition elicited more details than the Control and the Be detailed conditions. We believe that the Ghostwriter method worked better than the Be detailed instruction, because the Ghostwriter method gives interviewees a framework to use when they think about what is expected from them. That framework is probably easier to work with than following an instruction to be detailed. The Ghostwriter method may have encouraged truth tellers to fabricate information. We have no evidence that this was the case. In the post-interview questionnaire, participants indicated how much information they reported was truthful (in percentages). No significant main effect for Interviewer Instructions nor a significant Veracity x Interviewer Instruction interaction effect was obtained. However, this does not rule out a fabrication effect and future research should examine this.

Planned contrasts analyses showed that one difference between truth tellers and liars was most pronounced in the Ghostwriter condition: Plausibility. Truth tellers' stories sounded more plausible than liars' stories, particularly in the Ghostwriter condition. A possible explanation is that the Ghostwriter method encourages interviewees to say more than they normally would do. Truth tellers could therefore consult their memory and provide more information. In contrast, liars had to fabricate additional details and apparently struggle to come up with details that also sounded plausible. This resembles the finding obtained in Leal et al.'s (2015) Model Statement experiment. A Model Statement encouraged interviewees to say more than a standard no Model Statement condition, and the difference in plausibility between truth tellers and liars was most pronounced in the Model Statement condition. 
The Ghostwriter method did not make complications a more diagnostic cue to deceit. This is in conflict with Vrij et al.'s (2017b) Model Statement study where it was found that truth tellers reported more complications than liars, particularly in the Model Statement present condition. We believe the absence of such an effect in the current experiment is the result of being a victim of success. Complications was already a highly diagnostic cue to distinguish truth tellers from liars in the two other conditions, and that result was almost impossible to improve.

The Veracity main effects provided a replication of findings typically obtained in deception research: Truth tellers reported more details, more complications and fewer common knowledge details than liars. Truth tellers also obtained a higher proportion of complications score and truth tellers' stories sounded more plausible than liars' stories. The findings for details and plausibility are relatively well established (Amado, Arce, Fariña, \& Vilarino, 2016: DePaulo et al., 2003; Vrij, 2008), but the other findings are relatively new. The effect for verifiable sources was significant in the Ghostwriter condition, but not significant in the control condition. That means that we did not replicate Leal et al.'s (2018b) findings that truth tellers reported more verifiable sources than liars. In all other research concerning the Verifiability Approach to date, verifiable details rather than verifiable sources were examined and truth tellers typically reported more verifiable details than liars (Vrij \& Nahari, 2019). This suggests that a Veracity effect may be stronger for verifiable details than for verifiable sources, a hypothesis worth examining.

The variables complications, common knowledge details, self-handicapping strategies and the proportion of complications have now been investigated to our knowledge for the sixth time (see Vrij et al. [2017b, 2018b, c, d, e] for the earlier studies). Of those variables, complications and the proportion of complications seem 
to be the most diagnostic cues in all experiments to date. The results for common knowledge details and self-handicapping strategies are somewhat more erratic. Truth tellers sometimes report a similar amount of common knowledge details as liars and perhaps they do so when reporting something they find not important enough to discuss in detail. Self-handicapping strategies do not always distinguish truth tellers from liars, because they do not occur often. The results related to these three variables may therefore become stronger if investigators can implement techniques that make truth tellers less likely to report common knowledge details and liars more likely to report self-handicapping strategies (Nahari et al., 2019). Future research is warranted to design such techniques.

This study was not without its limitations. We did not ask truth tellers to report when the trip they talked about took place. However, Vrij et al. (2018e), who used the same scenario as used in the current experiment, did ask truth tellers when their trip took place. They found low, nonsignificant correlations (all r's $<.07$, all p's $>.50$ ) between this variable and total details, complications, common knowledge details, self-handicapping strategies, or proportion of complications. Vrij et al. (2018e) did not examine checkable sources or plausibility.

Another limitation is that we do not know yet why a Ghostwriter method would work. Is it simply the result of raising expectations to report more information? Or is it the result of a free-flowing memory recall in which presentation style does not matter and associations are allowed? Given that the method was somewhat more effective in truth tellers than liars suggests that the raising expectations explanation is the least valid explanation of the two, but future research should examine this.

We acknowledge that we carried out a rather basic test of the Ghostwriter method, which may be considered a limitation. We did this because it was the first 
ever test of this method and wanted to see first whether it had any potential. We believe further studies are required before suggesting implementing this method. These future studies could attempt to replicate the current basic experiment or to elaborate on it. For example, by comparing the Ghostwriter method with the Model Statement method in one experiment or to introduce the Ghostwriter method in a within-subjects design (initial free recall followed by the Ghostwriter instruction followed by a second free recall). The latter example will also make the interview protocol less basic (only one question was used in the current experiment).

\section{Acknowledgement}

This work was funded by the Centre for Research and Evidence on Security Threats (ESRC Award: ES/N009614/1) 


\section{References}

Amado, B. G., Arce, R., Fariña, F., \& Vilarino, M. (2016). Criteria-Based Content Analysis (CBCA) reality criteria in adults: A meta-analytic review. International Journal of Clinical and Health Psychology, 16, 201-210. Doi: 10.1016/j.ijchp.2016.01.002.

Brandon, S. (2011). Impacts of psychological science on national security agencies post9/11. American Psychologist, 66, 495-506. Doi: doi.org/10.1037/a0024818

Brandon, S. (2014). Towards a science of interrogation. Applied Cognitive Psychology, 28, 945-946. Doi: 10.1002/acp.3090.

Colwell, K., Hiscock-Anisman, C. K., \& Fede, J. (2013). Assessment Criteria Indicative of Deception: An example of the new paradigm of differential recall enhancement. In B. S. Cooper, D. Griesel, \& M. Ternes (Eds.) Applied issues in investigative interviewing, eyewitness memory, and credibility assessment (pp. 259-292). New York, U.S.A.: Springer. Doi 10.1007/978-1-4614-5547911.

Deeb, H., Vrij, A., Hope, L., Mann, S., Granhag, P. A., \& Lancaster, G. (2017). Suspects' consistency in statements concerning two events when different question formats are used. Journal of Investigative Psychology and Offender Profiling, 14, 74-87. Doi: 10.1002/jip.1464

DePaulo, B. M., Lindsay, J. L., Malone, B. E., Muhlenbruck, L., Charlton, K., \& Cooper, H. (2003). Cues to deception. Psychological Bulletin, 129, 74-118. Doi: $10.1037 / 0033-2909.129 .1 .74$

Du Prel, J-B., Hommel, G., Röhrig, B., \& Blettner, M. (2009). Confidence interval or p-value? Deutzches Arzteblatt International, 106, 335-339. Doi: 10.3238/arztebl.2009.0335. 
Ewens, S., Vrij, A., Leal, S., Mann, S., Jo, E., Shaboltas, A., Ivanova, M., Granskaya, J., \& Houston, K. (2016). Using the model statement to elicit information and cues to deceit from native speakers, non-native speakers and those talking through an interpreter. Applied Cognitive Psychology, 30, 854-862. Doi: $10.1002 /$ acp. 3270

Festinger, L. (1954). A theory of social comparison processes. Human Relations, 7, 117-140. Doi: $10.1177 / 001872675400700202$

Fisher, R. P. (2010). Interviewing cooperative witnesses. Legal and Criminological Psychology, 15, 25-38. Doi: 10.1348/135532509X441891

Fritz, C. O., Morris, P. E., \& Richler, J. J. (2012). Effect size estimates: Current use, calculations and interpretation. Journal of Experimental Psychology: General, 141, 2-18. Doi: 10.1037/a0024338

Granhag, P. A., \& Hartwig, M. (2015). The Strategic Use of Evidence (SUE) technique: A conceptual overview. In P. A. Granhag, A. Vrij, \& B. Verschuere (Eds.), Deception detection: Current challenges and new approaches (pp. 231-251). Chichester, UK: Wiley.

Hartwig, M., Granhag, P. A., \& Luke, T. (2014). Strategic use of evidence during investigative interviews: The state of the science. In: Raskin, D.C., Honts, C.R., Kircher, J.C. (Eds.), Credibility Assessment: Scientific Research and Applications (pp. 1-36). Oxford, UK: Academic Press.

Hartwig, M., Granhag, P. A., \& Strömwall, L. (2007). Guilty and innocent suspects' strategies during interrogations. Psychology, Crime, \& Law, 13, 213-227. Doi: $10.1080 / 10683160600750264$. 
Jarosz, A. F., \& Wiley, J. (2014). What Are the Odds? A Practical Guide to Computing and Reporting Bayes Factors. The Journal of Problem Solving, 7(1). Doi: $10.7771 / 1932-6246.1167$

Jeffreys, H. (1961). Theory of Probability. Oxford, UK: Oxford University Press.

Lakens, D. (2016, January 14). Power analysis for default Bayesian $t$-tests [Blog post]. Retrieved from http://daniellakens.blogspot.com/2016/01/power$\underline{\text { analysis-for-default-bayesian-t.html }}$

Leal, S., Vrij, A., Deeb, H., \& Jupe, L. (2018a). Using the Model Statement to elicit verbal differences between truth tellers and liars: The benefit of examining core and peripheral details. Journal of Applied Research in Memory and Cognition, 7, 610-617. Doi: 10.1016/j.jarmac.2018.07.001.

Leal, S., Vrij, A., Vernham, Z., Dalton, G., Jupe, L., Harvey, A., \& Nahari, G. (2018b). Cross-cultural verbal deception. Legal and Criminological Psychology, 23, 192-213. Doi: 10.1111/1crp.12131

Leal, S., Vrij, A., Warmelink, L., Vernham, Z., \& Fisher, R. (2015). You cannot hide your telephone lies: Providing a model statement as an aid to detect deception in insurance telephone calls. Legal and Criminological Psychology, 20, 129146. Doi: $10.1111 / 1 \mathrm{crp} .12017$

Loftus, E. F. (2011). Intelligence gathering post-9/11. American Psychologist, 66, 532541. Doi: $10.1037 / \mathrm{a} 0024614$

Nahari, G. (2018). The applicability of the Verifiability Approach to the real world. In P. Rosenfeld (Ed.). Detecting concealed information and deception: Verbal, behavioral, and biological methods (pp. 329-350). San Diego, CA: Academic Press. Doi: 10.1016/B978-0-12-812729-2.00014-8. 
Nahari, G., Ashkenazi, T., Fisher, R. P., Granhag, P. A., Hershkovitz, I., Masip, J., Meijer, E., Nisin, Z., Sarid, N., Taylor, P. J., Verschuere, B., \& Vrij, A. (2019). Language of Lies: Urgent issues and prospects in verbal lie detection research. Legal and Criminological Psychology, 24, 1-23.

Doi:10.1111/lcrp.12148

Nahari, G., \& Ben-Shakhar, G. (2011). Psychophysiological and behavioural measures for detecting concealed information: The role of memory for crime details. Psychophysiology, 48, 733-744. Doi: 10.1111/j.14698986.2010.01148.x

Nahari, G., Vrij, A., \& Fisher, R. P. (2014). Exploiting liars' verbal strategies by examining the verifiability of details. Legal and Criminological Psychology, 19, 227-239. Doi: 10.1111/j.2044-8333.2012.02069.x

Vrij, A. (2008). Detecting lies and deceit: Pitfalls and opportunities. Chichester, UK: John Wiley and Sons.

Vrij, A. (2016). Baselining as a lie detection method. Applied Cognitive Psychology, 30, 1112-1119. Doi: 10.1002/acp.3288

Vrij, A., Fisher, R., Blank, H. (2017a). A cognitive approach to lie detection: A metaanalysis. Legal and Criminological Psychology, 22, 1-21. Doi: 10.1111/lcrp. 12088

Vrij, A., \& Granhag, P. A. (2012). Eliciting cues to deception and truth: What matters are the questions asked. Journal of Applied Research in Memory and Cognition, 1, 110-117. Doi: 10.1016/j.jarmac.2012.02.

Vrij, A., Hope, L., \& Fisher, R. P. (2014). Eliciting reliable information in investigative interviews. Policy Insights from Behavioral and Brain Sciences, 1, 129-136. Doi: $10.1177 / 2372732214548592$ 
Vrij, A., Leal, S., \& Fisher, R. P. (2018a). Verbal deception and the Model Statement as a lie detection tool. Frontiers in Psychiatry, 9: 492. Doi: $10.3389 /$ fpsyt.2018.00492

Vrij, A., Leal, S., Fisher, R. P., Mann, S., Dalton, G. Jo, E., Shaboltas, A., Khaleeva, M., Granskaya, J., \& Houston, K. (2018b). Eliciting information and cues to deceit in interpreter-based interviews. Manuscript submitted for publication.

Vrij, A., Leal, S., Fisher, R. P., Mann, S., Dalton, G., Jo, E., Shaboltas, A., Khaleeva, M., Granskaya, J., \& Houston, K. (2018c). Sketching as a technique to elicit information and cues to deceit in interpreter-based interviews. Journal of Applied Research in Memory and Cognition, 7, 303-313. Doi:

10.1016/j.jrarmac.2017.11.001

Vrij, A., Leal, S., Jupe, L., \& Harvey, A. (2018d). Within-subjects verbal lie detection measures: A comparison between total detail and proportion of complications. Legal and Criminological Psychology, 23, 265-279. Doi:10.1111/lcrp.12126

Vrij, A., Leal, S., Mann, S., Dalton, G. Jo, E., Shaboltas, A., Khaleeva, M., Granskaya, J., \& Houston, K. (2017b). Using the Model Statement to elicit information and cues to deceit in interpreter-based interviews. Acta Psychologica, 177, 44-53. Doi: 10.1016/j.actpsy.2017.04.011

Vrij, A., Leal, S., Mann, S., Fisher, R. P., Dalton, G. Jo, E., Shaboltas, A., Khaleeva, M., Granskaya, J., \& Houston, K. (2018e). Using unexpected questions to elicit information and cues to deceit in interpreter-based interviews. Applied Cognitive Psychology, 32, 94-104. Doi: 10.1002/acp.3382

Vrij, A., Meissner, C. A, Fisher, R. P., Kassin, S. M., Morgan III, A., \& Kleinman, S. (2017c). Psychological perspectives on interrogation. Perspectives on Psychological Science, 12, 927-955. Doi: 10.1177/ 1745691617706515 
Vrij, A. \& Nahari, G. (2019). The Verifiability Approach. In J. J. Dickinson, N. Schreiber Compo, R. N. Carol, B. L. Schwartz, \& M. R. McCauley (Eds.) Evidence-Based Investigative Interviewing. New York, U.S.A.: Routledge Press.

Wetzels, R., \& Wagenmakers, E. J. (2012). A default Bayesian hypothesis test for correlations and partial correlations. Psychonomic Bulletin \& Review, 19, 1057-1064. Doi: 10.3758/s13423-012-0295-x 
Table 1

Statistical Results as a Function of Veracity

\begin{tabular}{|c|c|c|c|c|c|c|c|c|c|}
\hline & \multicolumn{2}{|c|}{ Truth } & \multicolumn{2}{|c|}{ Lie } & \multirow{2}{*}{$\boldsymbol{F}$} & \multirow{2}{*}{$p$} & \multicolumn{2}{|c|}{ Cohen's $d$} & \multirow[b]{2}{*}{$\mathbf{B F}_{10}$} \\
\hline & $M(S D)$ & $95 \% \mathrm{CI}$ & $M(S D)$ & $95 \% \mathrm{CI}$ & & & $d$ & $95 \% \mathrm{CI}$ & \\
\hline Motivation & $04.46(00.58)$ & $04.32,04.60$ & $04.25(00.68)$ & $04.11,04.39$ & 04.15 & .043 & +0.33 & $+0.00,+0.65$ & \\
\hline Preparation time & $05.39(01.65)$ & $05.05,05.73$ & $05.93(01.28)$ & $05.60,06.27$ & 05.11 & .025 & -0.37 & $-0.04,-0.68$ & \\
\hline Preparation thoroughness & $04.33(01.76)$ & $03.99,04.66$ & $04.79(01.10)$ & $04.46,05.12$ & 03.77 & .054 & -0.31 & $-0.01,-0.63$ & \\
\hline Percentage truth telling & $96.35(11.54)$ & $92.17,100.53$ & $15.66(22.88)$ & $11.53,19.78$ & 737.66 & $<.001$ & +4.44 & $+3.78,+4.96$ & \\
\hline \multicolumn{10}{|l|}{ Total sample $(N=150)$} \\
\hline Number of details & $39.16(17.89)$ & $35.66,42.27$ & $31.47(11.86)$ & $28.13,34.66$ & 10.38 & .002 & +0.51 & $+0.18,+0.83$ & 13.67 \\
\hline Number of complications & $06.50(05.64)$ & $05.48,07.50$ & $02.64(02.58)$ & $01.65,03.65$ & 28.68 & $<.001$ & +0.88 & $+0.54,+1.21$ & 50669.21 \\
\hline Number of common knowledge details & $02.85(02.76)$ & $02.26,03.42$ & $04.57(02.28)$ & $03.97,05.11$ & 17.27 & $<.001$ & -0.68 & $-0.34,-1.00$ & 366.25 \\
\hline Number of self-handicapping strategies & $00.18(00.58)$ & $00.04,00.32$ & $00.22(00.67)$ & $00.08,00.36$ & 00.15 & .700 & -0.06 & $-0.38,+0.26$ & 0.194 \\
\hline Plausibility & $04.57(01.16)$ & $04.33,04.78$ & $03.87(00.84)$ & $03.64,04.09$ & 18.43 & $<.001$ & +0.69 & $+0.35,+1.01$ & 493.46 \\
\hline Verifiable sources & $01.55(01.71)$ & $01.18,01.88$ & $01.07(01.37)$ & $00.72,01.42$ & 03.41 & .067 & +0.31 & $-0.02,+0.63$ & 0.972 \\
\hline Proportion of complications & $00.64(00.32)$ & $00.57,00.71$ & $00.32(00.28)$ & $00.25,00.39$ & 41.98 & $<.001$ & +1.06 & $+0.71,+1.39$ & 86240.06 \\
\hline \multicolumn{10}{|l|}{ Control condition $(n=51)$} \\
\hline Number of complications & $06.57(07.32)$ & $04.37,08.76$ & $02.29(02.45)$ & $00.30,04.27$ & 08.45 & .005 & +0.82 & $+0.23,+1.38$ & 7.77 \\
\hline Plausibility & $4.35(1.23)$ & $3.90,4.80$ & $3.82(0.95)$ & $3.41,4.23$ & 2.99 & .090 & +0.48 & $-0.09,+1.04$ & 0.95 \\
\hline
\end{tabular}


Number of details

Number of common knowledge details

Number of self-handicapping strategies

Verifiable sources

Proportion of complications

\section{Be detailed condition $(n=48)$}

Number of complications

Plausibility

Number of details

Number of complications

Number of common knowledge details

Number of self-handicapping strategies

Verifiable sources

Proportion of complications

\section{Ghostwriter condition $(\boldsymbol{n}=\mathbf{5 1})$}

Number of complications

Plausibility

\begin{tabular}{|c|c|c|c|c|c|c|c|c|}
\hline $35.83(15.23)$ & $30.40,41.25$ & $30.07(10.72)$ & $25.16,34.99$ & 02.50 & .121 & +0.45 & $-0.12,+1.00$ & 0.78 \\
\hline $02.22(02.41)$ & $01.25,03.18$ & $05.04(02.22)$ & $04.16,05.91$ & 18.84 & $<.001$ & -1.22 & $-0.60,-1.80$ & 295.76 \\
\hline $00.30(00.88)$ & $-0.04,00.65$ & $00.21(00.79)$ & $-0.20,00.53$ & 00.15 & .701 & +0.11 & $-0.45,+0.66$ & 0.30 \\
\hline $1.00(1.76)$ & $0.47,1.63$ & $1.00(1.48)$ & $0.43,1.57$ & .000 & 1.000 & 0.00 & $-0.55,+0.55$ & 0.28 \\
\hline $00.67(00.35)$ & $00.55,00.80$ & $00.27(00.25)$ & $00.16,00.39$ & 21.91 & $<.001$ & +1.34 & $+0.71,+1.39$ & 795.56 \\
\hline $05.68(04.04)$ & $04.36,07.00$ & $02.26(02.16)$ & $00.89,03.64$ & 13.04 & .001 & +1.04 & $+0.42,+1.63$ & 39.60 \\
\hline $04.28(00.94)$ & $03.94,04.62$ & $03.65(00.71)$ & $03.30,04.00$ & 06.73 & .013 & +0.76 & $+0.17,+1.32$ & 4.05 \\
\hline $33.92(17.63)$ & $28.31,39.53$ & $26.39(08.20)$ & $20.54,32.24$ & 3.50 & .068 & +0.54 & $-0.04,+1.11$ & 1.17 \\
\hline $05.68(04.04)$ & $04.36,07.00$ & $02.26(02.16)$ & $00.89,03.64$ & 13.04 & .001 & +1.04 & $+0.42,+1.63$ & 39.60 \\
\hline $03.68(03.57)$ & $02.54,04.82$ & $04.43(01.70)$ & $03.25,05.62$ & 00.85 & .361 & -0.26 & $-0.83,+0.31$ & 0.41 \\
\hline $00.12(00.33)$ & $00.01,00.23$ & $00.04(00.21)$ & $-0.07,00.16$ & 00.90 & .348 & +0.29 & $-0.29,+0.85$ & 0.41 \\
\hline $01.40(01.47)$ & $00.72,02.08$ & $01.13(01.89)$ & $00.42,01.84$ & 00.31 & .582 & +0.12 & $-0.43,+0.68$ & 0.33 \\
\hline $00.59(00.34)$ & $00.47(00.70)$ & $00.29(00.23)$ & $00.17(00.42)$ & 12.11 & .001 & +1.01 & $+0.41,+1.61$ & 28.63 \\
\hline $07.23(05.36)$ & $05.11,08.95$ & $03.40(02.99)$ & $01.65,05.15$ & 09.83 & .003 & +0.88 & $+0.29,+1.44$ & 12.94 \\
\hline $05.04(01.18)$ & $04.64,05.44$ & $04.12(00.78)$ & $03.72,04.52$ & 10.62 & .002 & +0.92 & $+0.32,+1.49$ & 17.30 \\
\hline
\end{tabular}


Number of details

Number of common knowledge details

Number of self-handicapping strategies

Verifiable sources

Proportion of complications

$\begin{array}{ll}47.15(18.12) & 40.85,53.46 \\ 02.62(01.94) & 01.68,03.55 \\ 00.12(00.43) & -0.13,00.36 \\ 02.19(01.72) & 01.65,02.74 \\ 00.66(00.29) & 00.54,00.79\end{array}$

$37.72(13.45)$

$31.29,44.15$

$04.16(02.75)$

$00.40(00.76)$

$03.21,05.11$

$00.15,00.65$

$00.52,01.64$

$01.08(01.48)$

$00.39(00.34)$

$00.26,00.52$
04.43

05.41

02.71

08.23

09.61
.041

\begin{tabular}{ccc}
\hline+0.59 & $+0.02,+1.14$ & 1.67 \\
-0.65 & $-0.08,-1.20$ & 2.44 \\
-0.46 & $-1.00,+0.11$ & 0.85 \\
+0.69 & $+0.11,+1.25$ & 7.16 \\
+0.86 & $+0.27,+1.42$ & 11.95 \\
\hline
\end{tabular}


Table 2

Statistical Results as a Function of Interview Instructions Condition

\begin{tabular}{|c|c|c|c|c|c|c|c|c|c|}
\hline & \multicolumn{2}{|c|}{ Control } & \multicolumn{2}{|c|}{ Be detailed } & \multicolumn{2}{|c|}{ Ghostwriter } & \multirow[b]{2}{*}{$\boldsymbol{F}$} & \multirow[b]{2}{*}{$p$} & \multirow[b]{2}{*}{$\eta_{p}^{2}$} \\
\hline & $\mathrm{M}(S D)$ & $95 \% \mathrm{CI}$ & $\mathrm{M}(S D)$ & $95 \% \mathrm{CI}$ & M (SD) & $95 \% \mathrm{CI}$ & & & \\
\hline Motivation & $04.31^{\mathrm{a}}(00.58)$ & $04.15,04.49$ & $04.60^{\mathrm{b}}(00.57)$ & $04.42,04.77$ & $04.16^{\mathrm{a}}(0.67)$ & $03.98,04.32$ & 06.64 & .002 & .08 \\
\hline Preparation thoroughness & $03.96^{\mathrm{a}}(01.58)$ & $04.04,04.81$ & $05.36^{\mathrm{b}}(01.54)$ & $04.77,05.55$ & $03.66^{\mathrm{a}}(01.43)$ & $93.71,04.47$ & 07.77 & .001 & .10 \\
\hline Number of details & $32.67^{\mathrm{a}}(13.13)$ & $28.96,36.94$ & $30.31^{\mathrm{a}}(14.30)$ & $26.06,34.26$ & $42.53^{\mathrm{b}}(16.54)$ & $38.46,46.41$ & 10.05 & $<.001$ & .07 \\
\hline Complications & $04.22(05.61)$ & $03.21,05.65$ & $04.04(03.67)$ & $02.72,05.22$ & $05.35(04.73)$ & $04.10,06.53$ & 01.21 & .301 & .02 \\
\hline Common knowledge details & $03.76(02.69)$ & $02.93,04.32$ & $04.04(02.83)$ & $03.34,04.77$ & $03.37(02.47)$ & $02.69,04.08$ & 00.90 & .409 & .01 \\
\hline Self-handicapping strategies & $00.25(00.82)$ & $00.09,00.43$ & $00.08(00.28)$ & $-0.10,00.26$ & $00.25(00.63)$ & $00.09,00.43$ & 01.31 & .273 & .02 \\
\hline Plausibility & $04.06^{\mathrm{a}}(01.10)$ & $03.81,04.36$ & $03.98^{a}(00.89)$ & $03.69,04.25$ & $04.59^{\mathrm{b}}(01.10)$ & $04.31,04.85$ & 05.48 & .005 & .07 \\
\hline Verifiable sources & $01.00(01.48)$ & $00.58,01.42$ & $01.28(01.67)$ & $00.83,01.70$ & $01.65(01.48)$ & $01.21,02.06$ & 02.23 & .111 & .03 \\
\hline Proportions of complications & $00.45(00.36)$ & $00.39,00.56$ & $00.45(00.32)$ & $00.35,00.53$ & $00.53(00.34)$ & $00.44,00.61$ & 00.99 & .375 & .01 \\
\hline
\end{tabular}

Note. Only mean scores with a different superscript differ significantly $(p<.05)$ from each other. 
